\title{
Workplace ESL at Levi Strauss: "Dropouts" Speak Out
}

\author{
Bonny N. Peirce \\ Helen Harper \\ Barbara Burnaby
}

This paper investigates why over 50 workers who qualified for ESL training did not participate in the EWP programs offered on-site at two garment factories in Canada. Findings are drawn from a research project commissioned by Levi Strauss \& Co. (Canada) in 1990. Results indicate that advertised programs, supervisor resistance, production and income anxiety, domes- tic and social pressure are more likely to lead to "dropout" than limitations in the programs per se. The authors conclude if an EWP program is to be effective, it must address not only the linguistic needs of the ESL workforce in a particular context, but its relationship to larger social and economic structures in the workplace and wider community.

Workplace English as a Second Language (ESL) training, also known as EWP, is a rapidly developing branch of the field of English for Specific Purposes (ESP). Like other branches of ESP, such as English for Science and Technology (EST) and English for Academic Purposes (EAP), EWP is characterized by a concern with the language learning and teaching of an identifiable group of adults within a specific learning context (Johns \& Dudley-Evans, 1991). According to Strevens (1988), the distinguishing characteristics of ESP are its focus on the specific needs of the learner within a particular setting and the development of appropriate language curricula and materials to meet predetermined goals. The benefit of ESP is that it is considered by its proponents to be more relevant, efficient, and cost-effective than general purpose English.

However, as Johns and Dudley-Evans (1991) point out, few empirical studies have been conducted to test the effectiveness of ESP courses. The purpose of this paper is to present some of the results of an EWP research project commissioned by Levi Strauss \& Company, the manufacturer of Levi jeans. While a full account of the study and its results can be found in Burnaby, Harper, and Peirce $(1990 ; 1992)$, this paper will focus on one of the questions that was addressed to the research team by Levi Strauss management, namely: Why do some people drop out or refuse to go to the English class? Unless the needs of "dropouts" are addressed, the full potential of EWP will not be realized. We hope that the results of this investigation will be of interest to curriculum planners, teachers, and researchers in other EWP contexts. 


\section{THE PROJECT}

In late 1989, Levi Strauss \& Co. (Canada) commissioned a research team at the Ontario Institute for Studies in Education, Toronto, Canada, to conduct an evaluation of the EWP programs in three of their garment factories in Canada. The garment factories are located in Stoney Creek and Brantford in southwestern Ontario, and Edmonton in Alberta. The purpose of the research was to evaluate the social impact of the EWP programs on both participants and non-participants at the three respective plants. The stakeholders included plant management, supervisors, ESL workers and English first language workers. Data collection began in February 1990 and was completed by June, 1990 (Burnaby, Harper, \& Peirce, 1990; 1992).

The EWP program in Edmonton is structurally distinct from those in Stoney Creek and Brantford. The program in Edmonton, run by English Language Professionals, is offered only after work during the week and on Saturday mornings, while the programs at Stoney Creek and Brantford are offered during the course of the working day. The participation rate at Edmonton is high: 29 per cent of the non-Canadian born ESL employees participate in this program, approximately 143 in total. In Stoney Creek and Brantford, participation rates are much lower: in Brantford only $8 \%$ of 239 ESL employees participate in the ESL class (approximately 20 workers) while the number in Stoney Creek is $18 \%$ of 222 ESL employees (approximately 40 workers). We found no evidence that the workers in Edmonton were in greater need of EWP training than those in Stoney Creek and Brantford. In addition, both participants and non-participants at Stoney Creek and Brantford expressed little interest in an after-hours EWP class. Reasons for the lower participation rates at Brantford and Stoney Creek must be sought elsewhere. The scope of our paper is therefore to investigate why many ESL workers at Stoney Creek and Brantford did not participate in the EWP programs in their respective plants. In the discussion of our findings, we also examine why the Edmonton program was particularly successful. 


\section{DATA COLLECTION}

Given that our original research project was broader in scope than the particular focus of this paper, the data collected on "dropouts" or non-participants were collected in the course of our regular interviews with a wide range of employees, including management, supervisors and line workers. We conducted interviews with the English language teachers, the plant managers, the human resources managers and assistants, the training managers, the plant nurses, instructors, shop stewards, and line workers. Group interviews were conducted with the ESL classes and the supervisors. In each interview we conducted (whether with individuals or groups) we asked the interviewee/s if they knew of anybody in the plant who had dropped out of the ESL course, who had been reluctant to attend, or who "should have been" in the class.

By word of mouth, we were able to track down 57 ESL workers for individual interviews. All of these workers were eager to improve their English skills, but for the reasons discussed below, had dropped out, or were either reluctant or unable to attend the EWP program in their plant. Of the total number, 33 had never attended an EWP class; the remainder had either dropped out or been unable to continue receiving ESL instruction. They all constitute the "dropout" or "non-participant" sample on which our findings are based. Although data from our interviews cannot claim to be definitive, the interviews, which lasted between 15 and 30 minutes, did yield sufficient data to enable us to draw a number of conclusions. In addition, data gathered from interviews with managers and supervisors increased our data base.

In order for us to appreciate many of the issues that arose during the course of the interviews, it was necessary for us to become familiar with the working conditions in the plant, the nature of the work undertaken by employees, the makeup of the workforce, the communication patterns on the factory floor, and the relationship between the EWP program and the culture of the plant. We were given an extensive tour of the plants, regularly observed machine operators at their stations and in the cafeteria, and spoke informally to the workers. We collected documents (application forms, teaching materials, plant memos) and examined teaching resources. Two of the three researchers underwent a training program with a group of new workers and attended an informal management/worker troubleshooting meeting. 


\section{OBSERVATIONS}

\section{Plants and Operations}

Both the Stoney Creek and Brantford plants are located in the relatively densely populated area of southern Ontario which tends to draw new immigrants in search of employment. The Stoney Creek plant is a sewing facility where jeans are cut and sewn, while the Brantford plant is a laundry facility where garments are laundered, pressed, repaired, and packed for distribution. At the time we conducted our research, the piecework system was in operation, although it is currently being eliminated. The piecework system is designed to maximize productivity-the more "bundles" of a particular operation have been completed, (risers or zippers etc. at Stoney Creek; pressed or packed jeans at Brantford) the more compensation the worker will receive.

When workers enter the plants they are greeted by a vast array of bewildering images and discordant sounds. In Stoney Creek, row upon row of women, and the occasional man, bend over sewing machines, surrounded by trolleys piled high with jeans in various stages of production. The workers are divided into sections, each of which performs a particular operation: risers, zipper, pockets, inseam, and fellseam. In Brantford, the operations are different from those in Stoney Creek since the operations performed in Brantford involve washing, repairing, labelling, and packing. In both plants, the supervisors and instructors regularly check production lists, consult with workers, and confer with fellow supervisors. The noise of hundreds of machines fills the air, and the strains of music piped through the intercom system can barely be heard.

\section{Workforce}

In the Stoney Creek plant, the total number of employees is approximately 370,70 of whom are salaried employees. The remainder are piecework or hourly workers. The machine operators are all piecework employees and $95 \%$ of them are women. A number of them have been at Levi Strauss for over 10 years, have well-established networks of friends, and are familiar with their jobs and the company; many workers, however, are recent immigrants to Canada and new to Levi Strauss. The majority of the workforce (approximately 60\%) speaks English as a second language, while the remainder is Canadian-born and speaks English as a first language. 
A wide variety of ethnic groups are represented in the plant, with the dominant groups being Italian, Slavic, East Indian, and Latin American. Eight of the nine plant supervisors speak more than one language and are generally representative of the ethnic composition of the plant floor. The shift begins at $7 \mathrm{am}$ : there is a ten-minute break in the morning, a ten-minute break in the afternoon, and half an hour for lunch. When the day ends, the workers clock out, and almost within minutes, silence descends on the plant.

In the Brantford plant, there are approximately 478 employees, 78 of whom are salaried workers; the remainder are either hourly or piecework employees. The workforce is predominantly female $(80 \%)$; the small minority of male employees are concentrated in the wash and warehouse sections of the plant. 50\% of the plant are non-Canadian born. The ethnic composition of the plant has changed dramatically over the past decade, from a predominantly white Canadian-born workforce to a racially and culturally diverse plant composed of many recent immigrants. The largest ethnic minorities are from are China, Vietnam, and Poland. The supervisors in this plant, emerging from the earlier workforce, are predominantly white Canadian-born women who speak only English and have been at the plant over ten years. There are three shifts at Brantford: a morning (160 workers), afternoon (160 workers), and midnight ( 80 workers) shift.

\section{Communication Patterns in the Plants}

In both the Stoney Creek and Brantford plants, many different languages are used on the shop floor and in the cafeteria. Most of this communication takes an oral rather than written form. Employee-driven communication needs include discussing machine or quality problems with supervisors or instructors (trainers); reporting work completed to supervisors; reporting conflicts to supervisors; interacting with human resources (absenteeism, illness, etc); and participating in union meetings, committees and clubs; interacting socially on the floor and in the cafeteria. Management, supervisors and operators have developed a variety of strategies to deal with some of these communication needs. In general, supervisors communicate in a formulaic English-what has been referred to as "Levi-English". In Stoney Creek, however, where most of the supervisors speak a second language, the tendency is to communicate in the language that is seen to be most effective and efficient at the time. Designated employees serve as interpreters in management/worker communication, but there is also a great deal of 
informal translation in the plants. While most of the communication in the plant is oral, noticeboards outside the cafeterias display safety regulations in a number of different languages. Other notices (union, community involvement, fundraising) are in English.

There is little evidence of social conversation on the plant floor. All the operators are intensely preoccupied with their work and if they leave their machines, it is generally to fetch new bundles of jeans. The opportunity for learners of English to practice their English is therefore minimal. The people with whom ESL workers communicate in English are predominantly supervisors, although, as one supervisor said, the piecework system tends to inhibit even this limited means of communication:

If we do get rid of piecework, right,-it'll always be a quota, but possibly not as stressful and productive oriented-we'll have more time to be able to talk to our people and-we, we still talk to them, but not as much as you'd like to. You just don't have the time all the time.

In the canteen, employees tend to sit with members of their own ethnic groups, where the use of the mother tongue is the most acceptable medium of communication. (See Goldstein, 1991, for further analysis of mother tongue usage in workplace settings.) English speaking Canadians in the plants generally have their own friendship networks, and tend not to socialize with non-English speakers. For this reason, the role of supervisors as "language teachers" is crucial because the supervisors have more English language contact with the operators than any other group of people in the plant. Since the supervisor has the most individual contact with operators, the role of the supervisor in encouraging operators to use English and helping learners express themselves is crucial. As one interview indicates:

Interviewer: Do you speak English when you're working?

Worker: I don't have chance to speak.

Interviewer: You don't have chance to speak?

Worker: $\quad$ No, I can't.

Interviewer: Why, why not?

Worker: Because I must, I must working. I don't have - Maybe sometimes I need something, I asking it.

Interviewer: Who do you speak to?-The supervisor?

Worker: $\quad$ Ya. The supervisor. Um, I'd sayInterviewer: Anybody else? 
Worker: $\quad$ Maybe now my instructor [trainer].

\section{The ESL Programs}

In Stoney Creek, the English language class has a long history. It began in 1979 when the human resources manager began teaching ESL to immigrant workers after hours. In 1982, Levi Strauss \& Co. (Canada) initiated a language curriculum development project for the ESL garment workers in this plant, and the EWP program became a more integral part of the plant (Bell, 1982). The EWP kit, developed by Bell, sought to provide a predominantly oral language course at the basic and intermediate level. Today, the English language teacher at Stoney Creek is employed on a parttime basis, 6 hours per week, by a local board of education. At the time the research was undertaken, there were two English language classes-a beginner and intermediate class-which each met three times a week for an hourly session.

Workers are informed about the EWP program when they are hired at the Stoney Creek plant, and they can confer with their supervisors as to when they would like to take the course. They use their half-hour lunch break for the class, while Levi Strauss pays the workers for the other half hour of class time, an amount determined by the workers' quarterly production averages. Workers generally buy their lunch in the cafeteria before coming to class and then eat their lunch while the class is in progress. Because of continuous intake, the number of workers in the classes changes fairly regularly, and there are no clearly defined entrance or exit tests. During the course of our research there were approximately 15 to 20 workers in each class. There has been high turnover of teachers in the program and a general lack of continuity from one teacher to the next. For example, from July 1989 to February 1990, the workers had four different teachers. The teacher we interviewed had no knowledge of the curriculum and materials that Bell had developed.

The EWP program in the Brantford plant began in 1987 and the teacher at the time of our study was under personal contract with the company. Two classes are available for workers both on day and afternoon shifts, but at the time of our study there was no program specifically for the midnight shift. There was an average of five workers per class-i.e. 10 workers per shift with a total of 20 workers enrolled in the EWP program in the plant. The teacher indicated, however, that she could accommodate more workers in the class. When the program began in 1987, there were in fact a total of 40 workers enrolled in the program. Like Stoney Creek, 
three hours of instruction per week are given and workers give up their half-hour lunch break and eat during the lesson. The other half-hour is subsidized by Levi Strauss. There is no distinct advanced and beginners program, but most of those attending at the time of our research could be considered beginners. Unlike Stoney Creek, there is no continuous intake into the ESL program; rather, 17-week sessions are offered. Workers are not informed about the program during their orientation to the plant and learn about the program by word of mouth through co-workers and supervisors. In addition, it is the supervisor who decides if a worker is in need of ESL training. If a worker is given permission to attend the course, the worker is still required each teaching day to secure permission from the supervisor to attend class.

\section{FINDINGS}

Many of our interviews with EWP non-participants were undertaken with the help of interpreters. This is not surprising given the fact that we, as anglophones, would have had great difficulty understanding ESL workers who "should have been" in the ESL program. While all the non-participants had complex and multiple reasons for their lack of participation in the EWP program, their reasons generally fell into one or more of the categories outlined below. It is not possible to provide statistical information about which factors were more pivotal than others in leading to dropout because the factors are interdependent. For example, if a worker is under pressure at home, he or she is more likely to be susceptible to production anxiety or peer pressure at work. In addition, the major reasons for dropout differ in each plant. Thus while supervisors contribute to the dropout rate in Brantford, they generally play a supportive role in Stoney Creek. Finally, we did not find striking differences between those employees who had dropped out and those who had never participated in the EWP programs. Needless to say, however, only those who had participated in a program could confidently comment on its effectiveness. On the basis of careful analysis, we have listed the reasons for "dropout" in what we consider to be relative degrees of importance.

\section{1. "Nobody asked me before": Lack of Promotion of Program}

Many non-participants we interviewed said they knew very little, if anything, about the EWP program. This is despite the fact that at 
the Stoney Creek plant, all new workers with limited English skills are informed of the EWP program when they are hired. In general, many of the operators we interviewed said that nobody speaks about the English course. The EWP program seems to have very little presence at either of the plants-there were no posters advertising the course, and no handouts for new workers. Although some nonparticipants knew about the program, they did not know who it was designed for, and whether they had the right to attend the program. As the interpreter said in one interview:

Nobody didn't tell her to go. She didn't feel like to ask nobody. You know, when you come from the other country, you feel shy. Some kind of-you think somebody can go, somebody couldn't.

The lack of promotion of the course in both plants can be contrasted with the high profile given to production goals. In one plant, large banners were displayed at the entrance of the cafeteria to indicate that target goals had been reached; in another, names and pictures of "President's Club" members, highly productive workers, were prominently displayed. The English course was peripheral to mainstream events in the plants, and in general, nobody (including management and union representatives) actively took on the responsibility of promoting the program. Ironically, it was our presence in the plants that raised awareness about the program; many of our interviewees asked us how they could participate in the program and when the next course would begin.

\section{2. "I can't let her go": Resistance of Supervisors}

As in many industrial settings, the supervisor has a crucial role to play in the work experience of employees (Jupp, Roberts, \& CookGumperz, 1982). At Levi Strauss, for example, the supervisor allocates new bundles of jeans to workers when they have completed a set. Some bundles are easier to handle than other bundles because of the type of fabric used and the size and cut of the jeans. A worker in one plant indicated that her supervisor always gave the "good" bundles to the Canadians and the "bad" bundles to the immigrants. For this reason, she needed ESL to defend herself from unfair treatment. According to one of the plant managers, the supervisor is a "god" to many of the workers. The manager described how an employee had refused to engage in conversation with the manager until the supervisor's permission had been 
obtained. Given the pivotal role that the supervisors play in the lives of the workers, a worker will not insist on attending an ESL class unless the program is supported and promoted by the supervisor.

In Stoney Creek, the supervisors did not have complete control over worker attendance in the EWP program because workers were encouraged by the human resources personnel to attend the EWP program if they were experiencing communication difficulties on the factory floor. In addition, all but one of the supervisors spoke a second language, and they were representative of the ethnic composition of the workforce. In general, they seemed to play a very supportive role in encouraging workers to attend the EWP program; some "walked" new workers to the ESL class to encourage attendance. On only one or two occasions did a non-participant claim that her supervisor had been reluctant to give her permission to attend class. "They told her there were too many girls in the class", explained one interpreter. The supervisors in this plant were generally not perturbed by the fact that one-and-a-half hours of production time per week were lost when a line worker attended an ESL class.

In Brantford, in contrast, the supervisors had complete authority to determine who was to attend the EWP program and when the workers could go. In addition, they were all anglophone, monolingual Canadians, and had experienced some difficulty in adapting to the transition from an anglophone workforce to a multicultural, multilingual workforce. While they were prepared to allow workers with very limited English skills to attend the program, they were less inclined to encourage more proficient speakers to participate. Furthermore, once workers had completed a 17 -week course, supervisors were often reluctant to send the workers back to the EWP program, despite the expressed interest of the workers. Some of the supervisors at Brantford expressed concern that workers attending the EWP program did not make sufficient use of English on the factory floor. As one said, "They still talk to each other in their own language. Shouldn't they be practising?"

It is important to note, however, that part of the ambivalence the Brantford supervisors felt towards the EWP program arose from their uncertainty as to what status the program had in the company and for whom it was designed. As one supervisor said:

If we could get an answer from them [management], how many do they expect to go. Do they want them all to go, or do they just want the really really bad ones to go that don't understand 
the English, or do they want the broken English people, or is it all? I just don't know. If this is going to be a priority, and this is what they want, let us know.

The supervisors indicated, in addition, that they did not know how to balance the demands of production with the interests of the workers, saying that "the line still has to keep running". As one said:

I would feel $100 \%$ better if I knew exactly what the company wants. Then I wouldn't be thinking that poor person that I'm stopping-and then I'm thinking production, production. You know, and you're torn in the middle and you don't know which end to go.

\section{3. "She gets so nervous": Demands of Production}

For many ESL workers at the plants, the job at Levi Strauss is the first job they have had in Canada, and they do not want to jeopardize their job security. Job security is determined by the worker's ability to achieve what is called "their $100 \%$ "-the minimum productivity level required to maintain their positions at the company. Some of the non-participants felt nervous and anxious during the ESL class because they were thinking of work that needed to be done and mistakes that needed to be corrected. As one interview indicates:

Worker: $\quad$ The thing is, sometimes I make a lot of mistakes at my work, and I'm think about it. I want the class finish fast so I can go back to work to look at the work.

Interviewer: So are you saying that when you come here, you're thinking, you're a bit worried about your work back on the floor, and you want to go back and fix it up and get more work done.

Worker: Ya.

Interviewer: And yet, here you're learning?

Worker: Ya.

Interviewer: And you're being paid.

Worker: $\quad$ Ya I know, I know.

Interviewer: But you still want to go back and work?

Worker: Still thinking, ya. Like sometime-OK-when I don't have no mistake or nothing, I feel OK, but 
sometimes I feel-I know, I know they pay for me, and everything-I don't know.

Some non-participants found that they lost momentum after the hour-long absence from the production line, and experienced reduced productivity. One interpreter explained: "If she comes to school, it's hard for her to get her percentage". Furthermore, the loss of momentum can also lead to an increased number of errors at the machine. When workers make mistakes, their productivity (and hence income) is reduced because of the time spent on "rejects". As one interpreter explained: "She gets so nervous, nothing goes right when she gets back". Even a seasoned worker claimed, "Rejects get on my nerves!"

One manager explained that many women "put the stress on themselves" by setting themselves higher and higher production goals. Although it was difficult to ascertain how much prestige is attached to high productivity levels, not only by management, but by workers, we often heard admiring comments about workers who performed at 140,150, and 160 percent. The following excerpt from a worker illustrates the kind of value that both workers and management place on high productivity and quality work, and the impact this has on a worker's self-concept:

I'm really smart for work...You know, when I see somebody, um make 150,160 , I want to beat, I want to make more, I want to beat-I want everybody talk about me, because I feel so -before, I feel nobody, like, nobody, I don't have nobody. I want to be something like-like yesterday they give us some award...it's a, like a sweater for everyone, for the whole section, because we don't have mistake for one day-I feel I want to cry.

\section{4. "She was afraid she would lose money": Anxiety over Compen- sation}

There was some confusion amongst the operators as to what kind of compensation they would receive when they attended the EWP program, and some non-participants said that they thought they would "lose money" if they enrolled in the program. Because compensation is based on the quarterly average of the workers, many of whom are in the process of become increasingly efficient in their operations, they do potentially "lose money" when they attend an ESL class. In other words, their quarterly average often does not 
reflect their current rate of productivity. Furthermore, if workers do lose momentum at their machines as a result of the hour-long English lesson in the middle of the shift, their productivity and income would decrease. The anxiety over compensation arose primarily, however, from a lack of knowledge about the relationship between the program and compensation.

\section{5. "Do they just want a break?": Resentment from Peers}

It was very difficult for us to ascertain how much resentment nonparticipants in the EWP program (anglophone Canadians as well as other non-participants) felt towards the ESL workers who participated in the EWP program-what someone referred to as a "company freebie"-and the extent to which this might have increased the dropout rate. An excerpt from an interview with one manager gives some indication of the complexity of the issue:

Interviewer: What is the response of the other workers to those who actually leave a particular section and go off to the English class?

Manager: Some people resent it.

Interviewer: Some of the other workers?

Manager: Yes.

Interviewer: Why, why?

Manager: They feel, "Why are we doing this for these foreign people?".

Interviewer: The people who resent it, are they native Canadians?

Manager: The majority, yes. Yes. They feel, "Why does the company sink all that money into-why don't they learn English before they come?" This type of thing. It's a kind of a prejudice.

Interviewer: But do you get that from other workers, non-English speaking workers?

Manager: Um, in some instances, yes. Like a few foreign people have said to me "Well, when I came to Canada, I had to look after myself. There was no employer...." Some people think it's a very good idea because they find "Hey, now I can talk to this person that's sitting next to me. Before she never opened her mouth because she was afraid to say something."

From our observations at the two plants we saw more evidence of peer resentment at the Brantford plant than at Stoney Creek. This 
might have been symptomatic of the general working atmosphere in each of the plants-a tone that develops over time and is perpetuated by management, supervisors, and workforce. In Stoney Creek, a "buddy" system has been established in which established workers help new workers to adjust to work and life in the plant. We found these "buddies", a number of whom were interpreters, to be helpful and supportive. "Even if they don't pay me", said one buddy, "I want to help the girls". In the Brantford plant, in contrast, one Canadian worker had been given a box of chocolates by an immigrant friend because her kindness was unprecedented; she said that her anglophone peers thought she was eccentric because she was friendly to immigrants. Another anglophone at Brantford commented: "Some people don't like people who don't speak English".

\section{6. "She didn't like the teacher": Limitations of Program}

Our findings indicate that if an EWP course does not help to promote the independence of workers both inside and outside the workplace, many workers may lose interest in the course. As the following excerpt indicates, the workers wish to learn to speak English to deal with problems that arise on the factory floor and to develop friendships with Canadians:

I was very angry and mad and crying-because of the mistake. Like, because I don't understand nothing and I don't know anybody Canadian people. Because I want to make friends but-because I don't know how to say or how to speak.

Another theme that ran through the comments of a number of non-participants was their desire to improve their reading and writing skills in English-a focus that was not a priority in both the Stoney Creek and Brantford programs. It is in this regard that the needs of the workplace, where communication patterns are primarily oral, may not coincide with the desires of some of the workers, who seek to develop literacy skills for use outside the workplace (see Cumming, 1990). As the following excerpt indicates:

Interviewer: So if the teacher was teaching you how to read and write, would that have been better?

Worker: Yes.

Interviewer: Would you like to stay? 
Worker: Yes. I want to know, I don't want to go out and somebody tell me the address or something, I don't want to say "Can you spell for me?"

Thus while the Levi Strauss course is billed as an "EWP" program, many workers attended the course, not only because they wanted to communicate more effectively on the factory floor, but because they wanted to become more independent outside the workplace. When one interviewer asked a worker why she needed reading skills for use in the workplace, she immediately responded by stressing its importance in the home:

Interviewer: What do you have to learn to read here in the factory? What do you have to learn to read? Why do you need to learn?

Worker: Because, first of all sometimes my son he wants notes for school, sometimes he have pain-I can't know how to start to write. "Dear", "Good morning", or something like this. Or good word, I can't, I just say: "My son have pains". That's it.

At the time our research was conducted, the Ontario plants did not cater to the specific needs of workers who were not literate in their mother tongues. These workers experienced particular difficulties in the classes, as one manager indicated:

Some people are quite illiterate, they have never gone to school. Some can hardly spell their own name. So that's scary for them, the fact of just the thought of going to school is scary for them.

Likewise, as one manager indicated, workers with low self-esteem were unlikely to participate in the course: "Some people feel shy. They feel they're not good enough; they feel they may be ridiculed."; one worker had indeed dropped out because she felt "dumb". Some found the level too low: "It's many people don't understand English", while a worker at Stoney Creek said it was a problem of class size: "She don't like too many people sit in the class", said the interpreter. One said she didn't like the teacher, while another said that she did not understand what the teacher was saying. 


\section{7. "I miss my friends": Need for Affiliation}

For many immigrant women, the workplace is the only place where they can meet other people outside their home environment "to see something, to talk, to go away from the house." Because of the limited opportunity to converse on the factory floor, the lunchbreak is an important time for workers to develop friendships and satisfy a need for affiliation. Some workers choose to withdraw from the EWP program in the interests of sharing lunchbreak with friends. In our study, one worker did not attend the EWP program because she did not have a co-worker who spoke her language, to "tell her what the teacher was teaching". Conversely, some workers attended ESL classes regularly precisely because they had developed friendships within the ESL class. The ESL class is a place where workers can meet friends in other sections of the plant, an opportunity otherwise unavailable because of staggered lunch hours. A disadvantage of this tendency, however, particularly in a continuous intake situation, is that a newcomer may feel isolated in a class where friendships (generally based on a common mother tongue) have been well-established. One worker indicated that she became irritated when her fellow workers spoke in their mother tongue during class.

Some people...they was sitting there they start talking the same language, their language, and bother me. Like, when I come in, but they start talk talk. We just want to speak English. Sometimes it bother me.

\section{8. "Her husband doesn't want her to learn English": Domestic Pressure}

It was difficult for us to determine to what extent the domestic pressures of workers in their homes led to non-participation in the EWP program. It was clear from a number of discussions however, that many women were working with only qualified support from their husbands: their husbands "allowed" them to work provided the work did not interfere with domestic responsibilities. One woman indicated that she gave her whole paycheck to her husband as an incentive for him to allow her to continue working:

I push myself to make good money because, I want him to be quiet like...he won't complain. I don't, I don't take nothing from the money, it's OK for me, I just want to work, I want to 
go away from the house, that's it. I give him the whole check. I don't care, even one bean. I don't care. "Do as you like, but just leave me to go out."

For some women, the privilege of working was not extended to attendance in the ESL class. As one manager said,

In some cases, people are reluctant because their husband doesn't want them to become smarter than they are, and they are not allowed to go. We've had that. We have some cases where people are reluctant to take homework home because their husband doesn't know that they're going to take it to school.

\section{DISCUSSION OF FINDINGS}

Our findings indicate that there is no simple answer to the question: Why do some people drop out or refuse to go to the English class? We found little evidence to support the view that "Some immigrants just don't want to learn English". It must be stressed that the vast majority of ESL workers at Levi Strauss were eager to improve their English skills, and would enthusiastically participate in the EWP programs at Levi Strauss if their working and domestic lives gave them this opportunity, and if the course was appropriate for their needs. We begin the discussion of our findings by comparing the well-attended Edmonton program with those in Stoney Creek and Brantford.

The fundamental differences between the Edmonton program and those in Brantford and Stoney Creek are: (i) The Edmonton program is conducted after hours. Workers do not experience the kind of production anxiety experienced by both workers and supervisors at Stoney Creek and Brantford-a major cause of nonparticipation at the Ontario plants. In addition, workers do not have to relinquish the opportunity to socialize with friends in their section during the lunch break. On the contrary, the after-hours program gives them even greater opportunity to satisfy their need for affiliation. (ii) The workers have full control over their participation in the program. They are informed of the program by the human resources personnel, and supervisors cannot exert a restraining influence over workers who wish to participate in the program. (iii) The workers are paid for the time they spend in the ESL class. They do not experience anxiety over a possible loss of 
income if they participate in the EWP program; on the contrary, the compensation they receive is over and above their regular wages. (iv) The program caters to learners who are not literate in the mother tongue, as well as to those who are literate, and a total of eight different proficiency levels are offered in the program. Few learners drop out of the program because of the size of the class or the level of difficulty of the class. (v) The teachers in the Edmonton program receive professional support and development from English Language Professionals.

It is important to note that while an after-hours EWP program suited the older and more established workforce at Edmonton, such a program was not considered a viable alternative in the Ontario plants (see Cumming and Gill, 1992, for a discussion of the relationship between length of residence of immigrants and participation in ESL programs). With few exceptions, the nonparticipants at Stoney Creek and Brantford indicated that they would be unable to remain after work to attend class because of their domestic commitments and childcare responsibilities. The following comments of one of the non-participants echoes numerous others: "I have to here because no time for me when I go home. No time for me to go evening to school. And when I get home I tired, work, you know." However, despite the appropriate timing of the class, some ESL workers did not attend the ESL classes for a variety of complex and related reasons: the program was not promoted in the company or endorsed by supervisors and coworkers; spouses were unsupportive; friendships were neglected. Some non-participants were anxious about production or a potential loss in income; others felt that the course did not meet their needs.

It is clear from these findings that if an EWP program is to meet what Johns and Dudley-Evans (1991) refer to as the "specific needs" of the learner within a particular setting, the program has to respond to both the linguistic needs of the learners as well as the learners' social and economic needs. It is precisely because EWP learners are part of a larger plant culture that the organizational structures and social relations of power in the workplace and wider community can jeopardize participation in an EWP program. It is highly ironic, for example, that the highest participation levels we observed were in the program that operated independently of workplace production and plant culture. However, since many workers cannot participate in after-work programs because of time constraints (see Hayes, 1989), EWP programs have to be sensitive to the organization of production and unequal relations of power in a given plant. Unless an EWP program addresses these issues, 
participation levels in a program may be low, no matter how relevant and communicative the curriculum.

\section{ADDRESSING THE "DROPOUT" PROBLEM}

On the basis of our observations and findings at all three plants, we have made the following analysis of the kinds of conditions that need to be met if EWP non-participation rates are to be reduced and greater participation encouraged.

1. Management and union representatives need to be unequivocal about their support for the program; the EWP program must be seen as a priority in the company and not "an add-on for immigrants". When new workers are hired-whether anglophone or ESL-it is important for them to be informed that EWP is a priority for the company, and that respect for this policy is expected of all employees. Furthermore, a commitment to EWP could be complemented with language and literacy skills training for all workers who desire it. This will help to reduce any resentment from workers who do not qualify for EWP training.

2. In order to give the program a high profile within the company, it should be actively promoted in the workplace through posters, handouts, union notices, and employee information packages, and written in the languages represented on the factory floor. The promotional material should make clear-to both ESL and anglophone workers - that the learning of English is a right and not a privilege that is granted under sufferance. This material should also clearly indicate that workers will not lose money if they take part in the EWP program.

3. Management should ensure that supervisors are educated about the company policy and that supervisors are not torn between the demands of production and the needs of the ESL workforce-tensions that are exacerbated when supervisors are given sole responsibility for controlling attendance in the ESL program. We suggest that conflict between supervisors and workforce, an important cause of dropout, is less likely to arise if supervisors are representative of the ethnic composition of the line workers and sympathetic to the needs of a multilingual and multicultural workforce. 
4. The elimination of the piecework system may reduce the production anxiety that many supervisors and workers experience and reduce anxiety that EWP participants might "lose money" if they attend the EWP program. In addition, it may also encourage more communication on the factory floor, particularly if a focus on teamwork is promoted.

5. The EWP program should make every endeavour to address the problems of ESL workers who are not literate in their mother tongue. A variety of levels should be made available to the ESL workforce, and literacy skills should be included in the curriculum. Peer tutoring (see Nore, 1990) could be an integral part of the EWP program.

6. Organizational links should be established between the EWP teacher, management, union, and supervisors to ensure that workplace communication needs are regularly addressed, and that continuity is established from one teacher to the next. Teachers should be compensated for time spent in such conferences.

\section{CONCLUSION}

A necessary condition of a regular ESP or EWP program is that it addresses the particular needs of a group of adult learners in a specific context. This ensures that the curriculum is relevant, communicative, and optimally designed. With reference to the content of EWP courses, both non-participants and regular participants in our study were in favour of a program that addressed not only the communication needs of the workplace but also of the wider community; in addition, many wished to develop both their oral and literacy skills. However, while the content of the EWP programs we evaluated may have had a bearing on the linguistic outcomes of the programs, it was not the major cause of "dropout" in the respective plants. Non-participation was more likely to result from social and economic forces than limitations in the programs per se. Our research indicates that there will be greater participation in EWP programs if the programs are well advertised; the management, supervisors and workforce supportive of the program; and production and income anxiety addressed. In essence, an effective EWP program must address not only the linguistic needs of the ESL workforce in a particular context, but its relationship to larger social and economic structures in the plant 
and wider community. In this way, an EWP program can best meet the needs of the ESL workers who say, "We'll never be like you, but we'll try".

\section{ACKNOWLEDGMENTS}

We would like to acknowledge the generous cooperation of all the Levi Strauss employees who made this study possible.

\section{THE AUTHORS}

Bonny Norton Peirce is a $\mathrm{PhD}$ candidate in the Modern Language Centre, Ontario Institute for Studies in Education (OISE), Toronto. Her research addresses the social and political context of second language learning, teaching, and testing, and is funded by the Social Sciences and Humanities Research Council of Canada.

Helen Harper is a PhD candidate in the Curriculum Department, OISE. Her research focuses on the politics of literacy and language pedagogy and its relationship to social identity. Her PhD thesis addresses the response of high school girls to feminist writing practices.

Barbara Burnaby is Chair of the Adult Education Department, OISE. Her research addresses ESL for immigrants in Canada, language issues concerning Native Canadians, and adult literacy. She has worked with many non-governmental organizations related to her research interests.

\section{REFERENCES}

Bell, J. (1982). The Levi Strauss project: Development of a curriculum. TESL Talk 13 (4), 82-91.

Burnaby, B., Harper, H., \& Peirce. B. (1990). Significant factors relating to ESL classes in three Levi Strauss plants (Research Paper). Toronto: Ontario Institute for Studies in Education.

Burnaby, B., Harper, H., \& Peirce. B. (1992). English in the workplace: An employer's concerns. In B. Burnaby \& A. Cumming (Eds.), Socio-political aspects of ESL education in Canada. Toronto: OISE Press. 
Cumming, A. (1990). The thinking, interactions, and participation to foster in adult ESL literacy instruction. TESL Talk, 20 (1), 3451.

Cumming, A. \& Gill, J. (1982). Motivation or accessibility? Factors permitting Indo-Canadian women to pursue ESL literacy instruction. In B. Burnaby \& A. Cumming (Eds.), Socio-political aspects of ESL education in Canada. Toronto: OISE Press.

Goldstein, T. (1991). The immigrant in the workplace: An ethnography of ways of communicating and experience at work. Unpublished doctoral dissertation, University of Toronto, Toronto.

Hayes, E. (1989). Hispanic Adults and ESL programs: Barriers to participation. TESOL Quarterly, 23(1), 47-63.

Johns, A. \& Dudley-Evans, T. (1991). English for Specific Purposes: international in scope, specific in purpose. TESOL Quarterly, 25(2), 297-314.

Jupp, T. C., Roberts, C., \& Cook-Gumperz, J. (1982). Language and disadvantage: the hidden process. In J. J. Gumperz (Ed.), Language and Social Identity. Cambridge: Cambridge University Press.

Nore, G. (1990). Peer tutoring in vocational literacy skills. TESL Canada Journal, 7(2), 66-74.

Strevens, P. (1988). ESP after twenty years: A re-appraisal. In M. Tickoo (Ed.), ESP: State of the art. Singapore: SEAMEO Regional Language Centre. 